\title{
Correction: Mobile Insight in Risk, Resilience, and Online Referral (MIRROR): Psychometric Evaluation of an Online Self-Help Test
}

Merel Marjolein van Herpen ${ }^{1,2}$, MA; Manon A Boeschoten ${ }^{3 *}, \mathrm{PhD}$; Hans te Brake ${ }^{1^{*}}, \mathrm{PhD}$; Niels van der $\mathrm{Aa}^{3}, \mathrm{PhD}$; Miranda Olff ${ }^{2,4}, \mathrm{PhD}$

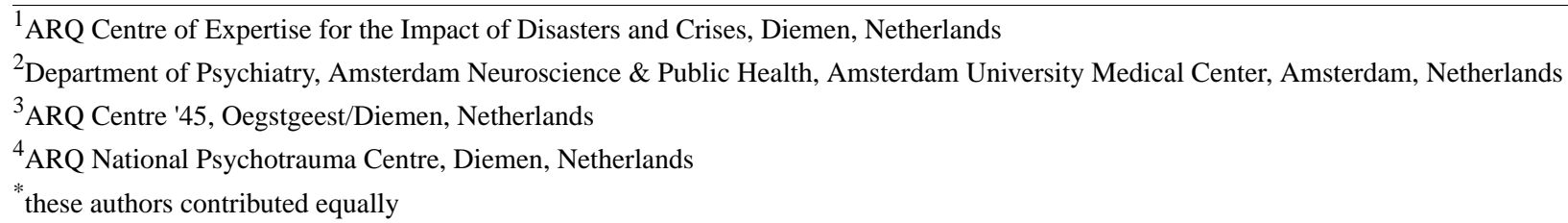

\section{Corresponding Author:}

Merel Marjolein van Herpen, MA

ARQ Centre of Expertise for the Impact of Disasters and Crises

Nienoord 5

Diemen,

Netherlands

Phone: 31610082023

Email: m.van.herpen@impact.arq.org

\section{Related Article:}

Correction of: https://www.jmir.org/2020/9/e19716/

(J Med Internet Res 2021;23(6):e29776) doi: 10.2196/29776

In "Mobile Insight in Risk, Resilience, and Online Referral (MIRROR): Psychometric Evaluation of an Online Self-Help Test" (J Med Internet Res 2020;22(9):e19716) one correction was made. This does not affect the analysis nor does it affect the interpretation or presentation of the results in the study.

In the "Methods" section, under "Measures" and "Depression, Anxiety and Stress", the following phrase appears:

A 5-point response scale measures the extent to which each state has been experienced over the past week ranging from 0 (not at all) to 4 (most certainly).
This has been replaced by the following:

A 4-point response scale measures the extent to which each state has been experienced over the past week ranging from 0 (did not apply to me at all) to 3 (applied to me very much, or most of the time).

The correction will appear in the online version of the paper on the JMIR Publications website on June 4, 2021, together with the publication of this correction notice. Because this was made after submission to PubMed, PubMed Central, and other full-text repositories, the corrected article has also been resubmitted to those repositories.

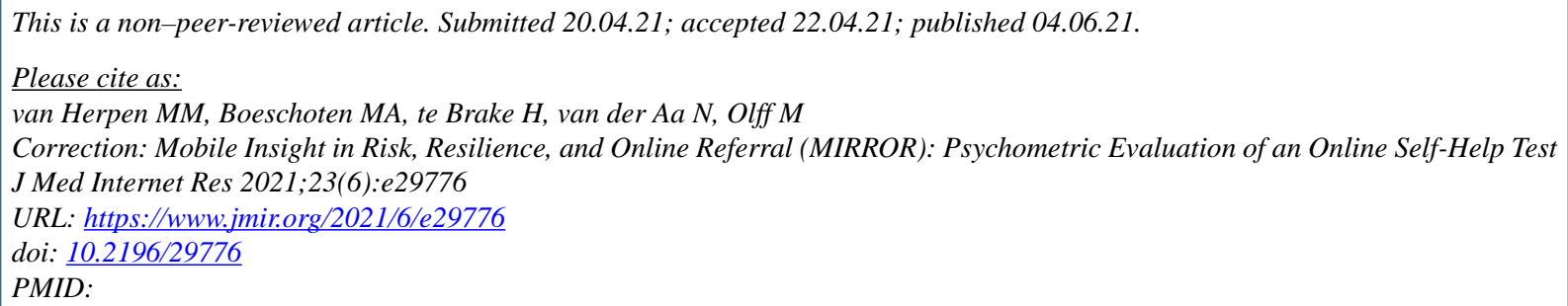

CMerel Marjolein van Herpen, Manon A Boeschoten, Hans te Brake, Niels van der Aa, Miranda Olff. Originally published in the Journal of Medical Internet Research (https://www.jmir.org), 04.06.2021. This is an open-access article distributed under the terms of the Creative Commons Attribution License (https://creativecommons.org/licenses/by/4.0/), which permits unrestricted use, distribution, and reproduction in any medium, provided the original work, first published in the Journal of Medical Internet 
Research, is properly cited. The complete bibliographic information, a link to the original publication on https://www.jmir.org/, as well as this copyright and license information must be included. 